\title{
SILÊNCIOS ATLÂNTICOS: SUJEITOS E LUGARES PRAIEIROS NO TRÁFICO ILEGAL DE AFRICANOS PARA O SUDESTE BRASILEIRO (C.1830 - C.1860)
}

Atlantic Silences: Subjects and Seaside Locations in the Illegal Traffic of Africans to the Southeast of Brazil (c.1830 - c.1860)

Silencios atlánticos: sujetos y lugares playeros en el tráfico ilegal de africanos hacia el Sureste brasileño (h.1830 - h.1860)

\footnotetext{
' Universidade Federal Fluminense (UFF), Niterói - RJ, Brasil

* Professor do Departamento de História da Universidade Federal Fluminense (UFF). (walterpereira@globo.com) ORCID iD: http://orcid.org/0000-0002-5688-8462

* * Pesquisador pós-doutor no Programa de Pós-Graduação em História da Universidade Federal Fluminense (UFF), com apoio da FAPERJ" (tcpessoa@hotmail.com) ORCID iD: http://orcid.org/0000-0001-8873-6511

Artigo recebido em 29 de outubro de 2018 e aceito para publicação em 28 de fevereiro de 2019.
} 


\section{RESUMO}

A ilegalidade do tráfico de africanos para o Brasil impôs profundos silêncios à sua história. No Sudeste, os desembarques de africanos eram sustentados por uma estrutura ajustada. Nas franjas do Atlântico, grandes propriedades praieiras serviam à recepção desses africanos. Seus donos, comendadores e nobres, animados pelo dinamismo do complexo cafeeiro, fundaram uma aristocracia ungida pela ilicitude. As fazendas negreiras e seus senhores reergueram o tráfico sob o manto da ilegalidade. Quebrar esse silêncio construído como política de Estado significa identificar sujeitos e lugares, valendo-se de indícios apresentados por uma cartografia de fontes pouco exploradas pela historiografia.

PALAVRAS-CHAVE: Tráfico ilegal de africanos; Praias atlânticas; Fazendeiros negreiros.

\section{ABSTRACT}

The illegal trade of Africans to Brazil imposed deep silences on their history. In the Southeast, the landings of Africans were supported by a tight structure. In the fringes of the Atlantic, large properties close to beaches were used to receive these Africans. Its owners, commanders and nobles, excitedby the dynamism of the coffee production, established an aristocracy anointed by illicitness. The slave farms and their masters reinstated the traffic under the cloak of illegality. Breaking this silence that was established as a State policy means identifying subjects and places, using evidence presented by a cartography of sources little explored by historiography.

KEYWORDS: Illegal Trade; Atlantic Beaches; Slave-based Farms.

\section{RESUMEN}

La ilegalidad del tráfico de africanos hacia Brasil impuso profundos silencios a su historia. En el Sureste, los desembarques de africanos eran sostenidos por una estructura ajustada. En las franjas del Atlántico, grandes propiedades cercanas a las playas eran usadas para recibir esos africanos. Sus dueños, comendadores y nobles, animados por el dinamismo de la caficultura, fundaron una aristocracia ungida por la ilicitud. Las haciendas negras y sus señores restablecieron el tráfico bajo el manto de la ilegalidad. Romper ese silencio construido como política de Estado significa identificar sujetos y lugares, valiéndose de indicios presentados por una cartografía de fuentes poco exploradas por la historiografía.

PALABRAS ClAVE: Tráfico ilegal de africanos; Playas atlánticas; Haciendas negreras. 
oão Tiago Von Tschudi, diplomata e nobre suíço, ministro plenipotenciário da Confederação Helvética no Brasil, empreendeu viagem ao longo das províncias do Rio de Janeiro e São Paulo entre 1858 e 1859. 0 registro dos caminhos percorridos naquelas paragens foi publicado na Alemanha sob o título de Viagens às Províncias do Rio de Janeiro e São Paulo (1958). Von Tschudi, em uma das passagens de seu relato de viajante, narra sua chegada ao extremo norte da província fluminense, oriundo do Espírito Santo, ao tocar fazendas a caminho de Campos dos Goytacazes. Portava uma carta de apresentação escrita pelo barão de Itapemirim, Joaquim Marcelino da Silva Lima, poderoso potentado do sul da província capixaba. O nobre brasileiro o recomendava a André Gonçalves da Graça, fazendeiro em São João da Barra, que prestasse o apoio necessário a sua empreitada.

André Gonçalves da Graça era português de Trás-os-Montes. Dedicara sua vida à travessia atlântica em navios negreiros, mantendo propriedades que chegavam até a orla atlântica do norte fluminense. Na percepção de Von Tschudi, tais viagens teriam sido muito lucrativas para o fazendeiro, por the permitir trocar o "sextante pelo arado"(ibidem; p. 15-16). Sua fazenda de São Pedro era vizinha de outra propriedade, ainda maior, "otimamente cultivadas" (ibidem; p. 16). Ambas surpreenderam o barão suíço "pela extensão, como pelas instalações e distribuição racional" (ibidem; p. 16): máquina a vapor, prensa de açúcar, monjolo de café, moinho de milho, serra circular. Modernidade escravista aos olhos de um nobre europeu. Além da produção de açúcar e café, mantinha indústria madeireira de "consideráveis lucros" (ibidem; p. 16) ao explorar as grandes matas que circundavam suas terras. Para escoar sua múltipla produção, Graça não encontraria maiores problemas, pois sua fazenda ficava a uma légua da costa, além de ser cortada por rios navegáveis, beneficiando-se de instalações portuárias nos limites fluviais com o Atlântico.

O relato de Von Tschudi, produzido na década de extinção do tráfico de africanos para 0 Brasil, ilumina um ponto ainda bastante obscuro na historiografia brasileira: o protagonismo de traficantes, negociantes e fazendeiros no comércio ilícito de africanos entre 1830 e 1860. André Gonçalves da Graça, por exemplo, já era notável fazendeiro quando, em 1851, fora capturado e arrolado em extenso processo na Auditoria Geral de Marinha, no Rio de Janeiro. Velho conhecido da repressão inglesa, capitaneada no Rio de Janeiro pelo diplomata britânico James Hudson, Graça era acusado de ser operador do tráfico transatlântico na ilegalidade, alvo da inibição circunscrita pelos tratados bilaterais anglo-brasileiros e, no início dos anos 1850, da execução das leis nacionais anti tráfico (Bethell, 1976). Não somente ele, como também outros senhores, detentores de ilícitas fortunas, operavam no tráfico ao longo da costa brasileira, com suas fazendas negreiras com logísticas para receber navios negreiros e operar 
a redução de indivíduos livres à escravidão, organizando da quarentena à redistribuição dos escravizados em mercados negreiros locais. Como desvendar a atuação desses homens num processo recoberto de silêncios institucionais, papéis destruídos, embarcações postas a pique, incendiadas, e dissimulações de toda a ordem para apagar os indícios do crime praticado no contexto de clandestinidade? Este é um problema que se impõe à história do tráfico durante sua ilegalidade no Atlântico, construída na primeira metade dos Oitocentos, e, no Império do Brasil, particularmente entre as décadas de 1830 e 1850, com suspeitas de desembarque até o início dos anos de 1860.Aqui, portanto, ampliamos o marco temporal visando encontrar evidências das ações de tais sujeitos e lugares descritos em três fontes diferenciadas: um relatório de época, produzido em 1853 (Alcoforado, 1853); um guia de fontes elaborado pouco mais de cem anos depois (Casadei, 1966); e um livro publicado em 1985 (Oscar, 1985) na perspectiva da história local, sobre uma das mais importantes áreas escravistas do Império. Levando em consideração as múltiplas possibilidades de fontes e acervos a serem explorados sobre o tráfico ilegal de africanos, utilizamos essas três referências como um exercício metodológico e ponto de partida do projeto "Fazendeiros negreiros: traficantes e tráfico ilegal de africanos no Rio de Janeiro (1830-1860)" . ' No sentido de enfrentarmos os silêncios "produzidos de indústria", como se dizia na época, pelo pacto entre Estado e sociedade escravista no Brasil sobre suas bases ilegais (Mamigoniam, 2011; Chalhoub, 2012), propomos uma ampla prospecção nos arquivos nacionais e estrangeiros a fim de qualificarmos melhor os lugares e os personagens que protagonizaram o reerguimento da escravidão no mundo atlântico pela reabertura do tráfico e sua sistematização nas nossas costas atlânticas, especialmente no que hoje chamamos de litoral sudeste brasileiro.

Para tanto, de início, montamos um quadro sucinto dos trabalhos que questionaram, em alguma medida, o silêncio sobre a ilicitude do comércio negreiro, deslocando a temática para o centro da agenda da historiografia sobre a escravidão no Brasil. Em seguida, cotejaremos as três fontes indicadas na perspectiva indiciária (Ginzburg, 1990: 143-179) atrás de pistas e rastros que nos conduzam ao mosaico de sujeitos e lugares relacionados ao tráfico ilegal de africanos para o Sudeste, com destaque especial para indicação de que fazendeiros fizeram fortunas ilícitas controlando barracões e fazendas negreiras nessa faixa litorânea. As três fontes elencadas reúnem evidências para recompormos as décadas finais do empreendimento atlântico entre o norte de São Paulo e o sul capixaba, camuflados na ilicitude do comércio negreiro e na conhecida cumplicidade do Estado imperial.

Nossa questão central será identificar sujeitos e lugares que protagonizavam a redução de indivíduos livres à escravidão em território nacional. Os recortes costeiros formados por 
praias, portos e ancoradouros, abrigavam fazendas, barracões e trapiches em pleno funcionamento. Tais locais serviam ao escoamento da produção e ao abastecimento das fazendas, ao mesmo tempo em que possibilitavam a reestruturação do tráfico, e, consequentemente da escravidão, no processo de expansão cafeeira pelo Vale do Paraíba. Nesse sentido, os grandes fazendeiros praieiros não se valiam dos negócios negreiros apenas de maneira utilitária, visando unicamente a mão de obra de seus plantéis. Ao contrário, estavam intimamente vinculados ao tráfico em sua dimensão atlântica, estruturando propriedades no litoral para sua finalização, sustentadas em redes de negócio transnacionais(Pessoa, 2015: 90-140; Pereira, 2018). Paralelamente às agências políticas, acionadas a fim de viabilizar a reabertura do comércio negreiro, esses senhores empreenderam a construção de complexos agrários e mercantis tendo por base a reorganização da logística traficante no litoral que margeava 0 extenso vale (Pessoa, 2018a; 2018c; Pereira, 2012b; 2018).

\section{A HISTORIOGRAFIA E SEUS COMBATES AO SILÊNCIO}

ilegalidade do tráfico de africanos no mundo atlântico passou a compor a agenda da
política externa luso-brasileira desde o início dos Oitocentos. De 1810 a 1817, tratados foram ratificados entre a Coroa Portuguesa e o Império Britânico a fim de abolir progressivamente o comércio de escravos para o principal porto negreiro das Américas, sediado na cidade do Rio de Janeiro. Com a Independência do Brasil, selava-se o último acordo da era legal do tráfico de africanos. A partir da prerrogativa britânica de reconhecimento da nação brasileira, em 1826, era estabelecida convenção que previa que o Império recém-criado aboliria o tráfico três anos após a ratificação do novo acordo, feita no ano seguinte (Bethell, 1976; Conrad, 1985). Assim, a partir de março de 1830, nos termos do tratado, o comércio negreiro entre a África e o Brasil era equiparado à pirataria. Essa nova condição levou à regulação interna do assunto e à aprovação do projeto do marquês de Barbacena, que originou a lei de 7 de novembro de 1831. Em seu artigo primeiro ficava estabelecido que "todos os escravos, que entrarem no território ou portos do Brasil, vindos de fora, ficam livres" (Brasil, 1831).

Entretanto, até o final da década de 1830, a perspectiva de aplicabilidade da lei de 1831 caminhou sempre acompanhada de seu questionamento, fosse por interesses políticos ou pela própria prática social escravista circunspecta à realidade brasileira (Rodrigues, 2000; Pessoa, 2010: 89-98; Parron, 2011). Somente após a renúncia da regência liberal de Feijó, em setembro de 1837, ascendendo ao poder Araújo Lima, os rumos da repressão ao tráfico mudariam. $\mathrm{Na}$ frente do novo gabinete, acumulando as pastas do Império e da Justiça, figurava Bernardo 
Pereira de Vasconcelos, maior representante do Partido Conservador e, àquela altura, arguto defensor da reabertura do tráfico negreiro em escala atlântica (Mattos, 2004). 0 regresso conservador, ao estabelecer-se no poder no início de 1838, facilitaria a reabertura do tráfico de maneira tácita, e assim o sustentaria durante toda a década de 1840, a despeito da repressão inglesa (Needell, 2006; Parron, 2011).

Somente no início da década de 1850, 12anos após intensa atividade traficante, quando cerca de 800 mil africanos foram ilegalmente reduzidos à escravidão no Império (Mamigoniam, 2017), o limite institucional, político e moral do tráfico foi definitivamente decretado. A lei de 4 de setembro de 1850, aprovada quando Eusébio de Queiroz ocupava a pasta da Justiça, incorporara e reafirmara os estatutos de outra lei,decretada em 7 de novembro de 1831, depois da tentativa fracassada de sua ab-rogação. A repressão decisiva nos primeiros anos da década de 1850 desenvolveu-se no mar, nas fazendas litorâneas e em instalações praieiras suspeitas de acolher os desembarques de africanos durante a ilegalidade (Pereira, 2011; 2012a; 2018;Pessoa, 2015: 90-140). De fato, as forças de repressão tinham informações possíveis e detalhadas dos desembarques e de sua complexidade, para identificar os principais agentes da clandestinidade (Ferreira, 1995; 2012; Pessoa, 2018b:165-206).

Em termos teóricos, fazendas, barracões, trapiches e mercados edificados no litoral, a fim de atender às demandas da produção cafeeirae, ao mesmo tempo, receber africanos ilegalmente importados, eram partes integrantes de uma estrutura histórica que atualmente a historiografia tem caracterizado como Segunda Escravidão (Tomich, 2011; Muaze; Salles, 2015; Marquese; Salles, 2016). 0 conceito surge como um importante instrumento para explicar o processo no qual, em pleno século XIX, a escravidão se reergueu em escala surpreendente no sul dos Estados Unidos, Brasil e Cuba, para atender à crescente demanda mundial de algodão, café e açúcar, respectivamente, movimento que em perspectiva global se inscreve em etapa renovada da Revolução Industrial e de expansão do capitalismo (Tomich, 2011; Blackburn, 2016). Na província do Rio de Janeiro, a população escrava saltou de pouco mais de 100 mil, em 1780 (Marcondes, 1995: 235-270), para quase 300 mil, em 1872 (Salles, 2008: 258-59)! Os desembarques contabilizados pelo site The Trans-Atlantic Slave Database, circunscritos à região costeira de Campos dos Goytacazes, entre os anos de 1838 e 1850, registram cerca de 48 mil africanos chegando às praias do norte da província, fazendo daquelas enseadas, ilhas e praias espaços privilegiados nos desembarques de negreiros no Atlântico. Frente a esses dados, insistimos que a reabertura do tráfico e sua sustentação tácita, por quase duas décadas, viabilizou o boom da economia cafeeira no Império. A construção de fortunas colossais dos fazendeiros negreiros esteve assentada nessa escravidão ilegal, não somente pelo fato desses 
senhores transformarem suas fazendas no resultado concreto dessas transações, mas, sobretudo, porque foram eles também os agentes que viabilizaram a logística e a estrutura política, social e econômica de retomada dos negócios negreiros em dimensões atlânticas (Pessoa, 2015, 2018c; Pereira, 2011, 2018).

Ainda que seja um tema amplamente discutido pela historiografia brasileira, os especialistas, seja pela escassez de fontes ou pela ênfase em análises no âmbito político, negligenciaram a estrutura de recepção dos africanos na costa brasileira e os agentes que operavam a complexa rede transcontinental de negócios que cortava o Atlântico. Se há consenso sobre a amplitude do comércio negreiro durante a década de 1840, quase nada sabemos acerca das estruturas de recepção e dos sujeitos que as operavam, não obstante referências de longa data a tais agentes serem citadas em fontes primárias, como no caso do relatório de Joaquim de Paula Guedes Alcoforado, de 1853. 0 compromisso do governo imperial com o ilícito trato, até a lei de 4 de setembro de 1850, fez com que o comércio negreiro não fosse efetivamente combatido, e, por isso, deixasse de ter registros. Operava-se o silêncio tácito como política de Estado sobre o comércio ilegal de africanos no processo de construção e consolidação do Império do Brasil (Mamigoniam, 2011; 2017; Chalhoub, 2012; Pessoa, 2018a)

As primeiras pesquisas acadêmicas sobre o período ilegal do tráfico de africanos se concentraram nos processos de elaboração de tratados de restrição e abolição do comércio negreiro entre 1810 e a aprovação da lei de 7 de novembro de 1831 (Goulart, 1949; Bethell, 1976). Quase ao mesmo tempo, outros estudos retomaram a discussão, aprofundando os significados e as consequências desses acordos para o comércio atlântico de almas (Conrad, 1985; Verger,2002). Nos últimos vinte anos, o campo de estudos sobre o tema desenvolveu-se a partir de análises que tomaram como mote diferentes dimensões do tráfico ilegal. Nessa perspectiva, foram analisadas as redes de relações comerciais transcontinentais no contexto de consolidação do capitalismo e de reestruturação dos negócios negreiros no Atlântico (Tavares, 1988; Ferreira, 1995;2012; Carvalho, 2012; 2016; Albuquerque, 2016).As experiências daqueles que de perto conheceram a diáspora africana na condição de vítimas de crime, tratado como nefasto aos princípios da humanidade e da moralidade universal, desde o Congresso de Viena, em 1815, também foram objeto de amplas pesquisas (Mamigonian, 2002, 2017; Rodrigues, 2005); além do processo de construção da ilegalidade e seu questionamento no parlamento, na política, e em parte da imprensa brasileira (Rodrigues, 2000; Parron, 2011; El Youssef, 2016).

Portanto, se a hegemonia e a ordem empreendida pelos conservadores garantia certa estabilidade política e institucional no processo de recrudescimento do tráfico, foi ele próprio resultado da tessitura do projeto hegemônico no Império do Brasil, no qual o fortalecimento da 
escravidão, por meiodo comércio ilegal de africanos, assumia papel edificante (Bethell, 1976; Mattos, 2004). Na prática social, fazendeiros e negreiros do extenso Vale do Paraíba, molas mestras da economia imperial, foram agentes protagonistas dessa construção hegemônica, atuando diretamente na retomada do tráfico, para muito além de suas agências políticas. Assim, somos levados a propor a análise do vínculo estruturante entre as maiores fortunas do Império e a migração forçada de cerca de 800 mil africanos sob do signo da ilegalidade (Pessoa, 2018c: 422-449). Uma relação que tem sua dimensão histórica na dinâmica dos sujeitos e lugares, nas redes de sociabilidade, nos vínculos políticos e em contornos econômicos estabelecidos por aqueles que na montagem do complexo cafeeiro escravista agiram igualmente em prol da retomada do tráfico no mundo atlântico na primeira metade dos Oitocentos.

Apesar do avanço no campo das pesquisas, os desembarques na clandestinidade em praias desertas do litoral brasileiro são quase sempre vistos como episódios fragmentados e desarticulados, com a exceção de análises mais recentes (Carvalho, 2012; Mattos, 2013; Pessoa, 2018c: 442-449; Pereira, 2012ab; 2018). Em contraste à generalização sobre o litoral brasileiro, os estudos que abordam o outro lado do Atlântico evidenciaram exatamente o contrário: uma complexa rede logística, econômica e política estruturada a fim de viabilizar os negócios negreiros, mesmo na ilegalidade (Ferreira, 1995; 2012; Capela, 2012).A repressão empreendida pelo abolicionismo inglês e a própria abolição do tráfico decretada por Portugal em 1836, se de um lado desarticularam as antigas estruturas negreiras estabelecidas na costa centro-ocidental africana, por outro lado provocaram a dispersão e a interiorização dos embarques para fora das zonas de controle português e, relativamente, protegidas da repressão britânica e da soberania europeia (Ferreira, 2012). Nesse aspecto, cresciam em importância os portos de Cabinda e Ambriz, ao norte de Luanda (Chichelli,2006; Wisembach, 2015), ao passo que se ampliava cada vez mais a participação do litoral moçambicano nos negócios negreiros no Atlântico (Capela, 2016).

Na costa brasileira,após aprovação da lei de 7 de novembro de 1831, as antigas estruturas portuárias de desembarque, acomodação e distribuição dos africanos recém-chegados foram desmontadas ao longo daqueles anos. Entretanto, antes mesmo da reabertura do tráfico em escala nacional, no final de 1830, a logística de desembarque, quarentena e redistribuição dos novos africanos foi refeita em outras bases e lugares, tendo à frente novos agentes, diferentes daqueles que empreenderam, financiavam e asseguravam os empreendimentos negreiros entre o final do século XVIII e as três primeiras décadas do século seguinte. (Carvalho, 2012; 2016; Mattos, 2013; Pessoa, 2015; 2018c:422-449)

Essa renovação estrutural do comércio de africanos representou mudanças também em relação aos negociantes que faziam funcionar as redes atlânticas. Comparando os grandes 
traficantes atuantes entre o Rio de Janeiro e a costa da África entre 1811 e 1830, com referências àqueles envolvidos no tráfico após 1831, somente José Bernardino de Sá já figurava ativamente nos negócios negreiros antes de 1830 (Florentino, 1997:254-256). Assim, parece patente que durante a clandestinidade houve um amplo processo de reestruturação e renovação das redes dos negreiros, possivelmente atrelada à maior proximidade entre traficantes e fazendeiros, marcando um novo padrão das relações de comércio no Atlântico. No entanto, ainda hoje, há um grande desconhecimento a respeito desses negociantes que atuaram na ilegalidade, lacuna apontada há quase duas décadas por Jaime Rodrigues (2000). Quando citados, aparecem quase sempre desvinculados de uma estrutura operacional organizada para a efetivação do empreendimento negreiro. Não custa lembrar que foram essas estruturas e esses sujeitos que possibilitaram a redução de milhares de africanos à escravidão ilegal no Brasil. Continuamos sem saber sobre a relação entre os traficantes, suas redes e a logística edificada no litoral brasileiro durante os anos de 1830 e toda a década seguinte. Por isso, acreditamos ser imprescindível conhecermos melhor os sujeitos que construíram e os locais que se tornaram cenários do reerguimento do tráfico na clandestinidade. Para tanto, voltamos ao nosso trio indicativo de fontes para nos somarmos àquelas pesquisas que buscaram, cada qual com a sua questão, romper o silêncio costurado pelos conservadores sob a habilidade do então ministro da Justiça, Eusébio de Queiroz. Eusébio, no início de 1850, prometera aos fazendeiros e à classe política não "resolver o passado", em referência a duas décadas de descumprimento da lei de 1831 e à escravidão ilegal de milhares de indivíduos (Pessoa, 2010:142-163). 0 compromisso do Estado brasileiro, no que chamaríamos hoje de garantia de segurança jurídica sobre o cativeiro amealhado na clandestinidade, assentava-se em fórmula simples na aparência e complexa no conteúdo: bastava silenciar em termos políticos a ilegalidade estabelecida antes de 1850, costurá-la juridicamente, considerando criminosos apenasaqueles que se mantivessem no tráfico a partir de setembro de 1850, assim como juridicamente livres somente os africanos desembarcados após o novo marco (Mamigonian, 2017; Pessoa, 2018a). A despeito das denúncias do abolicionismo já ativo no final dos anos de 1860, o arranjo saiu vitorioso à sua época, e se manteve por longo tempo na sociedade brasileira, incluindo nela seus historiadores.

\section{SUJEITOS E LUGARES: OS ELOS DA ILEGALIDADE SILENCIADA}

relatório de Joaquim de Paula Guedes Alcoforado (1853) foi o primeiro e um dos mais significativos inventários de sujeitos e lugares ligados ao tráfico ilegal de africanos no Rio de Janeiro. 0 documento, em tom de denúncia, fala sobre o passado que o Estado brasilei- 
ro não quis "resolver". Ao listar ano a ano a atuação dos envolvidos no comércio ilegal e os pontos de desembarques, o exímio conhecedor dos meandros do tráfico buscou a redenção de seu passado traficante, convertendo-se em informante do Foreign Office britânico no final dos anos de 1840, além de agente da repressão do Ministério da Justiça do Império do Brasil, no início da década seguinte (Ferreira, 1995). ${ }^{2}$ No ministério, além de se tornar estrategista da repressão, Alcoforado foi responsável pela comissão incumbida de apurar as denúncias recebidas, de produzir diligências e projetar o desmonte dos empreendimentos negreiros até, no mínimo, 1857 (Pessoa, 2018b: 165-206). Tarefa à altura de quem tinha intimidade com o negócio atlântico.

0 relatório de Alcoforado arrola sujeitos bastante conhecidos na capital negreira do Império, mas pouco evidentes hoje nas análises sobre a escravidão que abordam os meados dos Oitocentos. José Bernardino de Sá certamente é um deles. Destaque em seu relatório, Bernardino era velho conhecido de Alcoforado, com quem se correspondia enquanto prestava serviços aos dois impérios. 0 protagonismo de Bernardino de Sá no tráfico de africanos era patente e contumaz. Ao contrário da maior parte de seus pares que atuaram na ilegalidade, o português tinha estrada no negócio atlântico. Manolo Florentino (1997) o encontrou no rol dos negociantes de carne humana estabelecidos no Rio de Janeiro, em meados de 1820. As atividades do barão/visconde de Vila Nova do Minho começaram cedo. 0 primeiro desembarque sob os seus auspícios ocorreu em 1825. A embarcação partiu do Rio de Janeiro, arribou em Luanda, e de lá trouxe 466 africanos, 422 dos quais pisaram em solo carioca em 27 de julho daquele ano. ${ }^{3}$ Daí por diante, em diversos e diferentes navios, foram mais de 49 viagens! Dito de outra forma, somente no banco de dados The Trans-Atlantic Slave Trade Database, José Bernardino de Sá figura em meia centena de expedições como proprietário de tumbeiros que cruzavam o Atlântico, alcançando, inclusive, o litoral oriental da África, sobretudo os portos moçambicanos. Ao todo, entre 1825 e 1851, 19.022 africanos desembarcaram em 36 navios a ele consignados, alguns de sua propriedade. 0 barão/visconde português, títulos posteriormente reconhecidos pelo Império do Brasil, atuava no Atlântico, e no lado brasileiro estabeleceu fazendas praieiras em Ubatuba e São Sebastião, ao norte da província de São Paulo, espraiando-se pelo litoral fluminense, mantendo palacetes e casas de negócios na Corte e fazenda negreira em Macaé. Em Ambriz, ao norte de Luanda, montou barracões voltados ao comércio de escravos ao longo da década de 1840, a despeito da repressão inglesa, que incendiou um deles em 1842.

Entre os personagens alvos da pena de Alcoforado, duas outras figuras se destacam em sua mira: os comendadores André Gonçalves da Graça e Joaquim Thomaz de Faria, ambos 
citados como homens dotados de intimidade com o Atlântico: Graça foi reconhecido por ele como antigo marinheiro, que participou de diversas viagens à África. Faria foi patrão-mor, ou seja, principal prático do porto de São João da Barra, um dos mais importantes da província do Rio de Janeiro, onde trabalhavam, por volta de 1860, cerca de 700 homens, entre livres e escravos (Pereira, 2011, 2019). Em 1851, os dois já figuravam como grandes fazendeiros negreiros no norte fluminense quando se tornaram réus em processos instaurados pela Auditoria Geral de Marinha por tráfico ilegal de africanos.Ambos tinham relações com José Bernardino de Sá. Não se deve duvidar que até mesmo se agrupassem em uma espécie de confraria negreira. 0 próprio Alcoforado, antigo traficante, mantinha interlocução e laços de amizade com o catalão Francisco Ruviroza y Urgelles - referido também como Urzellas - figura de destaque no tráfico ilegal entre Cuba, Brasil, Estados Unidos e a costa da África (Nerín, 2016). Junto com eles estavam Elias José Alves e o português João Pedro da Costa Coimbra. Todos atados em uma rede restrita de grandes negreiros, com diferentes vínculos com o Atlântico escravista entre o final dos de 1830 e início de 1850.

André Gonçalves da Graça e Joaquim Thomaz de Faria concentravam seus negócios em São João da Barra e Campos dos Goytacazes, no extremo norte do Rio de Janeiro, onde ergueram um dos principais pontos de recepção ao tráfico ilegal no Império. Estima-se, segundo os dados do The Trans-Atlantic Slave Trade Database, que 74 mil africanos tenham desembarcado entre Campos e Macaé entre 1836 e 1850, configurando a maior zona de recepção negreira no Brasil no período da clandestinidade. Cumpre salientar que cerca de $60 \%$ da população de Campos dos Goytacazes, entre os anos de 1836 e 1850, era composta de escravos. 0 contingente de 38 mil cativos, em 1850, aproximava-se dos 39 mil cativos existentes, naquele mesmo ano, nos municípios de Valença e Vassouras juntos. Esses números indicam que os principais complexos agrários fluminenses rivalizavam na demanda por africanos durante a ilegalidade (Soares, 2015). Graça e Thomaz dominavam o tráfico na região do extremo norte fluminense, eram donos de embarcações, estaleiros, trapiches, barracões e engenhos, ao mesmo tempo em que cultivam cana de açúcar, café e atuavam como capitalistas locais. Ambos, comendadores no Império da ilegalidade, sustentavam um arco de relações sociais e políticas que iam muito além das suas praias, passando pela Corte, e atravessando o Atlântico, em portos europeus e africanos (Oscar, 1985; Pereira, 2018; 2019).

No rol dos traficantes identificados por Alcoforado estava um dos mais célebres articulistas do comércio ilegal ao sul da província do Rio de Janeiro, o comendador Joaquim de Souza Breves e seu irmão José de Souza Breves, possuidores de terras costeiras em Mangaratiba, Ilha Grande, Angra dos Reis, além da propriedade da Restinga de Marambaia. Os irmãos Breves 
mantinham relações com João Henrique Ulrich, português, proprietário de barracões no porto de Ambriz no início dos anos de 1840. No Brasil, Ulrich era dono da firma João Rodrigues Ulrich e Cia., casa comissária vinculada ao vale do café. Na intercessão café e tráfico, os Souza Breves mantinham também negócios com o negreiro Manuel Vieira de Aguiar, protagonista no tráfico para o Rio Grande do Sul nas primeiras décadas dos Oitocentos (Berute, 2011). Juntos dominavam os portos de recepção de africanos em Itaguaí e Mangaratiba, espraiando-se a Angra dos Reis com José Breves, dono da fazenda do Bracuí e ilhas anexas na baia da Ribeira (Pessoa, 2015: 90-140;2018c: 422-449).

Nesse arco de relacionamentos negreiros no sul fluminense, incluímos o comendador Antônio da Cunha Barbosa Guimarães, possuidor de barracões e fazendas em Dois Rios, na Ilha Grande, e seu irmão José Joaquim Guimarães, ambos proprietários da firma Guimarães \& Irmão, e responsáveis por desembarques na Ilha Grande, em Macaé e em portos do litoral da província do Rio de Janeiro. Segundo os dados do The Trans-Atlantic Slave Trade Database, 5.237 indivíduos atravessaram o Atlântico em navios de propriedade ou consignados pelos irmãos Guimarães (Pessoa, 2018b: 165-206).

Note-se que a família Souza Breves, especialmente os irmãos José e Joaquim, foram proprietários de um extenso complexo cafeeiro ao sul do Vale do Paraíba fluminense, que incluía praias, ilhas, restingas e portos no litoral meridional da província. Nesse caso, parece evidente que a montagem do complexo cafeeiro esteve indissociavelmente atrelada à reabertura do tráfico em escala atlântica. A partir da movimentação das casas comissárias do município de Mangaratiba, das redes de negócios tecidas naqueles espaços e na imensidão do Atlântico, das agências de repressão empreendidas pelas autoridades após 1850, sabemos que um dos maiores complexos de fazendas do Brasil imperial teve seu erguimento condicionado e estruturado pela reabertura do tráfico atlântico de africanos a partir de meados dos anos de 1830 (Pessoa, 2015: 90-140).

A cronologia apresentada por Alcoforado, delimitada entre os anos de 1833 e 1853, coincide com as mudanças conjunturais em torno do quadro político no Império. Nesse aspecto, o relatório destaca a reabertura e o impulso nos negócios transatlânticos a partir do "Regresso Conservador" e a intensificação da repressão inglesa nas margens atlânticas, em especial nas praias, portos, trapiches, barracões e deltas de rios que tocavam o litoral da província fluminense. A repressão inglesa depois da Lei Aberdeem abriu o leque dos desembarques na geografia praieira, pontuados pelo delator pago com recursos do serviço secreto inglês e pelo governo brasileiro: Dois Rios, Mangaratiba, Itha Grande, Cabo Frio, Rio das Ostras, Macaé, Campos, São João da Barra, Manguinhos e Itabapoana, com conexões no litoral sul do Espírito 
Santo, onde André Gonçalves da Graça mantinha propriedades; e ao norte da província de São Paulo, particularmente em São Sebastião e Ubatuba, onde José Bernardino de Sá também encontrava refúgio para fundear seus tumbeiros. A escalada do tráfico ampliava-se, fazendo das praias e ilhas desertas um porto seguro para os navios negreiros.

A prosperidade do negócio ilícito incluía o suborno de autoridades e a proteção política descarada ao comércio ilegal. Inclua-se, ainda, o envolvimento de empresas transnacionais que especulavam com o tráfico, como as portuguesas Maia Saraiva Patacão \& Barroso, e Guimarães Rocha Brandão e Cia., segundo o delator. Para escapar, os traficantes podiam contar com as defesas feitas por eminentes bacharéis, de alto calibre na Corte, como João Manoel Pereira da Silva, que, segundo Alcoforado, "ativou então sua carreira como defensor dos negreiros" na Assembleia Provincial Fluminense (Pessoa, 2010: 89-98) e fora dela (Parron, 2011: 224-230). Além de Pereira da Silva, contavam com João Siqueira Queirós, João Antônio de Miranda e os jurisconsultos Agostinho Marques Perdigão Malheiro (Pereira, 2019) e Augusto Teixeira de Freitas (Pessoa, 2018a).

Thalita de Oliveira Casadei (1966) talvez tenha produzido o primeiro guia de fontes para a identificação de sujeitos e lugares do tráfico ilegal na província fluminense. Numa agenda anual, a partir de 1835, Casadei montou um registro indicativo de ofícios e outros documentos trocados entre autoridades fluminenses e da Corte, como parte do acervo da "Sala de Estudos Fluminenses Matoso Maia", mantido na Biblioteca Pública do Estado, em Niterói. A maior incidência de documentos nesse intercâmbio ocorre a partir de 1850, quando da vigência da Lei Eusébio de Queiroz. Dos 100 papéis listados entre os anos de 1835 e 1855, 80 deles referem-se ao período posterior a 1850, denotando que o Estado brasileiro, deliberadamente, evitou ao máximo produzir prova que materializasse a ilegalidade da escravidão nacional entre 1830 e1850 (Mamigoniam, 2011).

Desde 1836, no entanto, num dos primeiros registros feitos por Casadei, já ficara evidente o envolvimento de autoridades locais no comércio ilegal de africanos, como no caso do juiz de paz do distrito de Taipu, padre Antônio Joaquim de Sá, além de Francisco Raimundo de Barros, Manoel Luz das Lindas Flores e Possidônio José de Souza. Notícias de desembarques envolvendo tais figuras evidenciam como as praias de Niterói, capital da província, eram bastante utilizadas por negreiros. Em um desembarque ocorrido na praia de Imbuí, naquele mesmo ano, na margem esquerda da barra de entrada da baía de Guanabara, os africanos foram levados às terras do major Lutero e de Francisco de Albuquerque. Em 1850, Eusébio de Queiroz alertou o presidente da província sobre desembarques em Jurujuba, outra praia contornada pelas tranquilas águas da baía de Guanabara, cenário da antiga vila do Arraial da Praia Grande. 
Logo, a capital da província era um ponto recorrente de desembarques ilegais desde meados dos anos de 1830. Nesse aspecto, podemos inferir que os desembarques, ainda que tenham se afastado das praias próximas à Corte, com a desarticulação da estrutura do Valongo, mantiveram-se em seus arredores. Exemplo disso está no alerta do presidente da província fluminense, Aureliano de Souza e Oliveira Coutinho, que, em março de 1848, comunicava às autoridades locais o desembarque de 900 africanos fora da barra do Rio de Janeiro, entre as fortalezas de São João e a praia Vermelha, a menos de 10 quilômetros do Paço Imperial.

Os documentos indicados no guia de fontes organizado por Thalita Casadei reportavam-se a desembarques em toda a extensão do litoral fluminense, de Paraty a São João da Barra. José Bernardino de Sá, além de outros traficantes estabelecidos em Macaé, surgem no alerta dado pelo chefe da legação britânica no Rio de Janeiro, Hamilton Hamilton, ao governo imperial, em 1842, de que o lendário traficante mantinha armazéns na cidade portuária do litoral norte, em que negreiros tinham trânsito direto com a costa da África. Bernardino de Sá também era suspeito de ter negócios com um traficante de nome Botelho, e de manter relações com as casas de Amaral \& Bastos Guimarães. Macaé, que passara a ser um ponto visado pelas autoridades, também figurava nas referências feitas por Eusébio de Queiroz sobre o desembarque do brigue Polka, em 1850, e nos indícios de que Francisco Jose da Conceição, residente na Rua da Praia, fazia negócios no ilícito trato. Havia, ainda, a suspeita de que o juiz municipal da vila, o bacharel Joaquim Augusto de Holanda Costa Ferreira, igualmente estivesse atrelado ao comércio de africanos, corroborando a desconfiança do governo com o comprometimento de autoridades locais com o tráfico ilegal, mesmo após a lei de 1850.

Em outro alerta citado por Casadei, o ministro da Justiça escreveu a respeito de diligências realizadas pela polícia em Cabo Frio e Rio das Ostras, dando conta da existência de "muitas pessoas", principalmente portugueses, a prestar auxílio aos desembarques. Em Cabo Frio havia o indicativo de cinco barracões ligados ao tráfico. Ali, em 1851, o cerco e 0 abate aos negócios do português e comendador José Gonçalves da Silva serviram de primeira punição a um traficante no litoral fluminense. Silva foi detido e teve confiscados seus bens arrolados no tráfico, destacando-se a primazia, o ineditismo e o caráter exemplar da medida punitiva aplicada pelo governo brasileiro, depois da lei de 1850. Seu drama foi posto em cena por um libelo publicado e lembrado de forma recorrente nos anos seguintes, em que o negociante de grosso trato, fortuna local, traficante, contrabandista, influente na cidade de Cabo Frio e na Corte, afirmou ter sido injustamente subtraído de seus armazéns, de seu barracão, de seu trapiche, e de demais bens, incluindo escravos, por suas ligações com práticas ilícitas pelo trato de africanos (Pereira, 2009; 2011). 
Armazéns e barracões eram locais citados com frequência na interlocução entre as autoridades. Como forma de coibir a participação de estrangeiros no negócio, Eusébio de Queiroz determinou ao presidente da província ativar o recrutamento na Marinha e no Exército para enquadrar aqueles envolvidos no tráfico ilegal. Para os estrangeiros, o engajamento deveria ser feito na Armada e, caso recusassem, deveriam deixar o País. Talvez, o tipo de coação atingisse especialmente cidadãos portugueses, pelo fato de serem homens dotados de maior intimidade com viagens atlânticas entre o Brasil e a África, como ocaso do comendador André Gonçalves da Graça. Às vésperas da nova lei, não havia mais pontos desconhecidos pelos operadores do comércio atlântico ilegal no litoral fluminense. As correspondências epistolares codificadas por Thalita Casadei pontuavam todo o recorte atlântico da província, de Mangaratiba a Itaguaí, na praia do Saí, na casa de F. Monte Bello, de uma ilha próxima à freguesia de Itacuruçá a suspeitas da existência de depósitos nas fazendas de Coroa Grande, no porto de Estrela, um dos mais frequentados por traficantes, e na praia de Ubatuba, em Quissaman, com o resgate da barca Tentativa, com 454 africanos a serem desembarcados em Cabo Frio, além de seus dez tripulantes, todos procedentes de Quilimane, na costa oriental africana.

Na vigilância empreendida no litoral sul da província, o guia de Thalita Casadei destaca a ação dos irmãos Breves, em que sobressaem declarações prestadas por Laureano Antônio Lopes Coelho, Domingos Antônio Lopes Coelho e Domiciano Rodrigues da Silva sobre africanos desembarcados em Coroa Grande, na localidade denominada Maromba, onde eram conduzidos "serra acima" por "um tal de Pimenta", sobrinho dos Breves, até a localidade de São João Marcos. Logo depois, descortina-se um desembarque na Coroa, no município de Itaguaí, conforme depoimento prestado ao juiz Luciano da Silva Rangel. 0 depoente dizia ter conhecimento da ação de guias para conduzir africanos da Restinga de Marambaia até as terras de Joaquim Breves. Em outra correspondência citada no mesmo guia de fontes, Eusébio de Queiroz repassa informações sobre Tomaz da Costa Ramos, o Maneta, que encomendou na Itália uma nova embarcação destinada ao tráfico, cuja construção estava a cargo de um armador em Gênova. $O$ trabalho no estaleiro era acompanhado por Vitor da Silva Freire, cidadão baiano, cunhado de Ramos.

Ao dar continuidade à política de repressão, Ildefonso de Souza Ramos, substituto de Eusébio de Queiroz no Ministério da Justiça, recomendou manter a vigilância sobre Bernardino Ferreira, em Niterói, e André Van Randvyk Schert, proprietário do patacho português Paquete de Loanda. 0 primeiro era proprietário da Lagoinha, no norte de São Paulo, e teve sua fazenda praiana devassada no início de 1856 sob a suspeita de servir de barracão para o tráfico ilegal. Um pouco antes, o ministro determinara aos delegados de polícia no litoral da província a 
captura de João Pedro da Costa Coimbra, português envolvido no desembarque do porto do Bracuí, em dezembro de 1852, um dos últimos e mais famosos casos de desembarque ilegal na imprensa da Corte (Abreu, 1995). Coimbra foi também citado por Alcoforado como alguém relacionado com o catalão Francisco Ruviroza y Urgelles. No avançar da década de 1850, as autoridades do Império mapearam as praias supostamente desertas que abrigavam as embarcações negreiras que cortavam o Atlântico. Os agentes vinculados ao tráfico ilegal teciam uma rede nesse caleidoscópio de nomes, constituindo-se, para nós, verdadeiros quebra-cabeças a serem montados pela história. Em relação aos lugares onde se praticava o crime de reduzir pessoas livres ao cativeiro em solo brasileiro, alista das praias litorâneas convertidas em pontos de recepção perpassava todo o litoral referenciado por Alcoforado e Casadei, do norte de São Paulo, entre Iguape e Ubatuba, ao sul do Espírito Santo, nas praias de Itapemirim a Benevente.

João Oscar (1985; 59-103), outro pesquisador no lastro de fontes sobre os negócios negreiros, apresentou documentos encontrados no Arquivo Nacional e na Biblioteca Nacional que evidenciam os meandros da ilegalidade ao norte da província do Rio de Janeiro. 0 primeiro destaque na obra de Oscar é a movimentação de embarcações no porto de São João da Barra. Ao apresentar uma amostra das entradas naquele porto entre 13 e 30 de janeiro de 1852, o autor revela expressiva cabotagem que passava por um dos principais portos da província, onde 30 navios diferentes haviam aportado ali naqueles 18 dias, além das entradas no porto de Itabapoana, no limite com a província do Espírito Santo. Oscar nomeia as principais figuras envolvidas e seus entrepostos mantidos no litoral: José Gonçalves da Silva e José Luiz Lopes Trindade, vulgo José do Peró, ambos atuando em Cabo Frio; João Antônio de Brito, Joaquim de Abreu da Silva Braga, Luiz Mendes Ribeiro, Manuel Soares, André Gonçalves da Graça e Joaquim Thomaz de Faria, em São João da Barra. Em Macaé, sobressaio italiano Victório Emanuel Paretto, deportado naquele ano de 1852, embora circulasse pela cidade protegido pelo delegado local;o já experiente José Bernardino de Sá; Joaquim Ferramenta; José de Souza Velho, talvez portador de relações de parentesco com a baronesa de Macaé, Leonarda Velho da Silva, segundo Manolo Florentino (1997: 192), uma das maiores fortunas envolvidas no tráfico na praça do Rio de Janeiro, antes de 1830, além de Francisco Domingues de Araújo. Na fronteira com a província capixaba foram citados Aurélio Jorge Silva Quintaes e Joaquim Marcelino, barão de Itapemirim, além de outros, atuando em Marobá, no Cerry e em Itapemirim, no litoral sul do Espírito Santo.

Nesse mosaico de nomes, ao contrário de sua aparente desconexão, os vínculos desses indivíduos ao tráfico ilegal de homens, mulheres e muitas crianças estreitam suas trajetórias. 
Ainda sabemos pouco sobre eles. Nomeá-los, como fizeram Alcoforado, e, mais de um século depois, Casadei e Oscar, são os primeiros passos para recuperarmos suas agências e responsabilidades históricas com relação a ilicitude que cometeram. Destaca-se que nos referimos à figuras da elite imperial, espalhada por vários cantos das províncias do Sudeste. Gente como André Gonçalves da Graça, que ocupou a vice-presidência da Câmara Municipal de São João da Barra, ou Joaquim Thomaz de Faria, que exerceu os cargos de delegado de polícia, patrão-mor do porto de São João da Barra e presidente da Câmara. Ambos eram comendadores da Ordem da Rosa e da Ordem de Cristo. Os dois importavam africanos que depois de internados em suas fazendas praieiras eram enviados para Campos, São Fidélis, Espírito Santo e Minas Gerais, não sem antes "adestrá-los", em termos de época, em suas terras. A dupla mantinha relações com José Bernardino de Sá, atuante no litoral de Macaé. Ali, encontravam-se expostos, segundo o diplomata britânico Hamilton Hamilton, três mil africanos novos em armazéns locais. Certamente, havia uma íntima conexão desses traficantes com a costa central atlântica africana e com o mar do Caribe, como evidenciam cartas apreendidas escritas de Luanda, Benguela, Ambriz e Havana (Oscar, 1985). As missivas foram assinadas por negreiros como Raphael de Toca, Francisco Antônio Flores, Luiz Mendes Ribeiro Abreu, e Salvador de Castro, em Havana; novamente Luiz Mendes, Bento Luiz Pereira e Manoel Domingues Dias Pereira, em Ambriz; além de Joaquim Antônio da Fonseca Guimarães, José Rodrigues Pinto Coimbra e Manoel da Silva Pereira Ramos Cardoso (idem). Sujeitos que fizeram funcionar a estrutura transatlântica que reatualizou o tráfico negreiro no segundo quartel dos oitocentos, mas ainda na penumbra nas análises históricas, encobertos pelo silêncio imposto pela ilegalidade.

\section{ARISTOCRACIA NEGREIRA: UMA IDEIA EM CONSTRUÇÃO}

F azendeiros negreiros atuaram na viabilização, na reabertura do tráfico e na revitalização da escravidão no Brasil. Reforçamos o argumento de que esses senhores agenciaram diretamente o processo de reestruturação do tráfico de africanos nos Oitocentos. Ao erguerem seus complexos agrários, tiveram por base a reabertura do comércio negreiro e sua estabilização na década de 1840. Portanto, as maiores fortunas imperiais, assim como a própria receita do Estado brasileiro, estiveram indelevelmente atreladas à reabertura e manutenção do comércio negreiro na clandestinidade. A construção da questão nesses termos garante uma abordagem inovadora de dois objetos erroneamente apartados da historiografia: a formação do amplo complexo cafeeiro da bacia do Paraíba, cuja extensão, paralela ao arco litorâneo da província do Rio de Janeiro, estende-se do norte de São Paulo ao sul do Espírito Santo; e o comércio negreiro em sua fase clandestina (Pessoa, 2015: 90-140). 
O exercício proposto pela análise do relatório Alcoforado, pelo guia de fontes de Thalita Casadei e pelos indícios apontados no livro de João Oscar faz ver que os espaços montados para a prática do crime de redução de indivíduos juridicamente livres ao cativeiro envolviam redes transatlânticas de negócios e poder. Da mesma forma, esses lugares serviam de suporte aos desembarques, à recuperação e à redistribuição de africanos destinados à lavoura açucareira e aos cafezais que cresciam nas bacias do Paraíba e do Itapemirim-Itabapoana. Note-se que não estamos nos referindo a simples portos de recepção de tumbeiros. A descrição dos bens dos comendadores Graça e Faria, dos irmãos Breves e do barão/visconde de Vila Nova do Minho revelam amplas propriedades costeiras, que poderíamos chamar de "complexos negreiros": ilhas, praias, barracões, trapiches, brigues e iates compunham patrimônios oceânicos postos a serviço da finalização dos empreendimentos negreiros. Ao longo do litoral brasileiro, outros complexos semelhantes foram montados com o intuito de reduzir indivíduos livres à escravidão e remontar a estrutura de mercados negreiros, semelhante ao Valongo, fechado na Corte como decorrência da lei de 7 de novembro de 1831. Sobre eles, sabemos muito pouco. Remontá-los em sua estrutura, funções e agências dos que os faziam funcionar é o primeiro passo para rompermos com o compromisso de silêncio alinhavado pelo Estado imperial brasileiro.

Vale destacar que devemos navegar em águas profundas para trazer de lá sujeitos ancorados na ilegalidade expressa pela diáspora forçada de milhares de africanos entregues à escravidão no Império do Brasil. Traficantes nobilitados pela monarquia brasileira e portuguesa, a despeito de afrontarem as leis nacionais, reconhecidos por negociar a "carne humana", como denunciava o jornal 0 Philantropo, expoente na imprensa abolicionista dos anos de 1850. Consolidava-se, assim, uma "aristocracia negreira". Comendadores e barões fizeram do crime profissão no Império do Brasil e, com esse ofício, amealharam fortunas colossais. Muitos, em seu descanso eterno, ocultaram-se por trás do compromisso do Estado, materializado nas palavras do então ministro Eusébio de Queiroz,de não "resolver o passado". Marca indelével da nossa história, agentes, lugares e a cumplicidade do País recém-fundado e de sua sociedade com negócios negreiros foram relegados intencionalmente ao esquecimento porque atentavam contra seus próprios estatutos jurídicos, contra a própria moralidade do mundo dito civilizado em meados dos Oitocentos, evidenciando, em última instância, a natureza da formação nacional e do mundo do trabalho em redefinição no Brasil. Nesse sofisticado arranjo, - Estado brasileiro cobriu com véu sedoso a aristocracia reinventada nos trópicos, livrando-a da adjetivação negreira, incensada pelo manto imperial. Confrontar o passado que se fez calar é desafio aberto e inconcluso, que procuramos encaminhar neste texto que se encerra como agenda para o futuro. 


\section{NOTAS}

10 projeto em questão foi proposto pelos autores, aprovado, e está sendo apoiado pelo Conselho Nacional de Desenvolvimento Científico e Tecnológico (CNPq), por meioda Chamada Universal MCTI/CNPq 28/2018, com previsão de término no início de 2022, culminando com a publicação de um livro sobre a reorganização dos negócios negreiros em sua fase ilegal do litoral que segue do sul do Espírito Santo ao norte de São Paulo.

20 relatório de Joaquim de P. G. Alcoforado foi publicado em tradução de sua versão inglesa por Ferreira (1995). Recentemente, republicamos o texto do relatório na versão entregue ao Ministério da Justiça do Império do Brasil, com pouquíssimas diferenças em relação à sua versão anterior (Pessoa, 2018a).

3 ver The Trans-Atlantic Slave Trade Database.

\section{REFERÊNCIAS BIBLIOGRÁFICAS}

ABREU, Martha. 0 caso do Bracuhy. In: MATTOS, Hebe; SCHNOOR, Eduardo (org.). Resgate: uma janela para os Oitocentos. Rio de Janeiro: Top Books, 1995.

ALBUQUERQUE, Aline. De "Angelo dos Retalhos" a visconde de Loures: a trajetória de um traficante de escravos (1818-1858). 2016. Dissertação (Mestrado em História) - Universidade Federal de Pernambuco, Recife. 2016.

ALCOFORADO, Joaquim de Paula Guedes. O tráfico ilegal de africanos de 1831 a 1853. S.I.:s.n., 1853. Arquivo Nacional / Fundo: Série Justiça IJ6 525.

BERUTE, Gabriel. 0 tráfico negreiro no Rio Grande do Sul e as conjunturas do tráfico atlântico, c.1790-1830. In: ENCONTRO ESCRAVIDÃO E LIBERDADE NO BRASIL MERIDIONAL, 5. 2011. Porto Alegre. Anais... Porto Alegre: s.n., 2011.

BETHELL, Leslie. A abolição do comércio brasileiro de escravos: a Grã-Bretanha, o Brasil, e a questão do comércio de escravos (1807-1869). Rio de Janeiro: Editora Expressão e Cultura; São Paulo: Edusp, 1976.

BLACKBURN, Robin. Por que segunda escravidão? In: MARQUESE, Rafael; SALLES, Ricardo (org.). Escravidão e capitalismo histórico no século XIX: Cuba, Brasil, Estados Unidos. Rio de Janeiro: Civilização Brasileira, 2016. p. 13-54.

BRASIL. Lei de 7 de novembro de 1831. Declara livres todos os escravos vindos de fôra do Imperio, e impõe penas aos importadores dos mesmos escravos. Rio de Janeiro, 1831. Disponível em: https://www2.camara. leg.br/legin/fed/lei_sn/1824-1899/lei-37659-7-novembro-1831-564776-publicacaooriginal-88704-pl.html. Acesso em: 23 de outubro de 2018.

CAPELA, José. Conde de Ferreira \& C. a. Traficantes de Escravos. Lisboa: Edições Afrontamento, 2012. O tráfico de escravos nos portos de Moçambique. 2. ed. Porto: Edições Afrontamento, 2016.

CARVALHO, Marcus J.M de. 0 desembarque nas praias: o funcionamento do tráfico de escravos depois de 1831. Revista de História, São Paulo, n. 167, p. 223-260, jul./dez. 2012.

Trabalho, cotidiano, administração e negociação numa feitoria do rio Benin em 1837. Afro-Ásia, Salvador, n. 53, p.227-273, 2016. 
CASADEI, Thalita de Oliveira (org.) Documentos sobre a repressão ao tráfico de africanos no litoral fluminense. Rio de Janeiro: Secretaria de Educação e Cultura/Departamento de Difusão Cultural/Biblioteca Pública do Estado do Rio de Janeiro/Sala de Estudos Matoso Maia, 1966.

CHALHOUB, Sidney. A força da escravidão: ilegalidade e costume no Brasil oitocentista. São Paulo: Companhia das Letras, 2012.

CICCHELLI, Ana Flávia. Tráfico ilegal de escravos: os caminhos que levam a Cabinda. 2006. Dissertação (Mestrado em História) - Universidade Federal Fluminense, Niterói. 2006.

CONRAD, Robert. Tumbeiros: o tráfico de africanos para o Brasil. São Paulo: Brasiliense, 1985.

EL YOUSSEF, Alain. Imprensa e escravidão: política e tráfico negreiro no Império do Brasil (Rio de Janeiro, 1822 - 1850). São Paulo: Intermeios /Fapesp, 2016.

FERREIRA, Roquinaldo. História sobre o infame negócio de africanos da África Oriental e Ocidental, com todas as ocorrências desde 1831 a 1853. Estudos Afro-Asiáticos, Rio de Janeiro, n. 28, p. 219-229, out. 1995.

.Dos sertões ao Atlântico: tráfico ilegal de escravos e comércio lícito em Angola, 1830-1860.Luanda: Editora Kilombelombe, 2012.

FLORENTINO, Manolo. Em costas negras: uma história do tráfico de escravos entre a África e o Rio de Janeiro. São Paulo: Companhia das Letras, 1997.

GINZBURG, Carlo. Sinais: raízes de um paradigma indiciário. In: . Mitos, emblemas, sinais: morfologia e história. São Paulo: Companhia das Letras, 1990.

GOULART, Maurício. Escravidão africana no Brasil: das origens à extinção do tráfico. São Paulo: Livraria Martins Editora, 1949.

MAMIGONIAN, Beatriz. To Be a Liberated African in Brazil: Labour and Citizenship in the Nineteenth Century. Ontário: University of Waterloo, 2002.

. 0 Estado nacional e a instabilidade da propriedade escrava: a lei de 1831 e a matrícula dos escravos de 1872. Almanack, Guarulhos, n. 2, p. 20-37, 2ํsem. 2011.

. Africanos livres: a abolição do tráfico de escravos no Brasil. São Paulo: Companhia das Letras, 2017.

MARCONDES, Renato L. 0 envolver demográfico e econômico nos espaços fluminenses (1780-1840). Estudos Econômicos, São Paulo, v. 25, n. 2, p. 235-270, maio/ago. 1995.

MARQUESE, Rafael; SALLES, Ricardo (org.). Escravidão e capitalismo histórico no século XIX: Cuba, Brasil, Estados Unidos. Rio de Janeiro: Civilização Brasileira, 2016.

MATTOS, Ilmar. O tempo saquarema. 5. ed. São Paulo: Hucitec, 2004.

MATTOS, Hebe (org.). Diáspora negra e lugares de memória: a história oculta das propriedades voltadas para o tráfico clandestino de escravos no Brasil imperial. Niterói: Eduff, 2013.

MUAZE, Mariana; SALLES, Ricardo (org.). O Vale do Paraíba e o Império do Brasil nos quadros da Segunda Escravidão. Rio de Janeiro: Faperj/7Letras, 2015.

NEEDELL, Jeffrey D. The Party of Order: The Conservatives, the State, and Slavery in the Brazilian Monarchy, 1831-1871.Stanford: Stanford University Press, 2006. 
NERÍN, Gustau. Falsos brasileños: las trayectorias africanas y americanas de los negreros españoles Derizans y Roviroza (1831-1863). Revista Latino-Americana de Estudos Avançados, v. 1, n.1, p. 96-85, jan./jun. 2016.

OSCAR, João. Escravidão \&engenhos - Campos; São João da Barra; Macaé; e São Fidélis. Rio de Janeiro: Achiamé, 1985.

PARRON, Tâmis. A política da escravidão no Império do Brasil, 1826-1865. Rio de Janeiro: Civilização Brasileira, 2011.

PEREIRA, Walter Luiz Carneiro de Mattos. De todos os santos a Lúcifer: uma história do tráfico e de traficantes depois do fim do tráfico. Niterói: Universidade Federal Fluminense, 2009.Anais Eletrônicos do POLIS, Laboratório de História Econômica.

José Gonçalves da Silva: tráfico e traficante de escravos no litoral norte fluminense, depois da lei de 1850. Tempo - Revista do Departamento de História da Universidade Federal Fluminense, Niterói, n. 31, p. 285-312, 2011.

Corredor infame: tráfico e traficantes de africanos nas praias fluminenses e capixabas, depois da lei de 1850.In: GUIMARÃES, Carlos Gabriel; PIÑERO, Theo Lobarinhas; CAMPOS, Pedro Henrique Pereira (org.). Ensaios de História Econômica Social. Niterói: Eduff, 2012a.

Além das fronteiras: tráfico ilegal e trilhas interprovinciais; In: CÔRTE, Andréa Telo da (org.) História fluminense: novos estudos. Niterói: Funarj/Imprensa Oficial, 2012b.

A trama da ilegalidade: tráfico de africanos no Sudeste brasileiro (1850-1860); In: XAVIER, Regina Célia Lima; OSÓRIO, Helen (org.). Do tráfico ao pós-abolição: trabalho compulsório e livre e a luta por direitos sociais no Brasil. São Leopoldo: Oikos, 2018.

Fazendeiros ou culpados? Comendadores no tráfico ilegal de africanos. Revista do Arquivo da Cidade do Rio de Janeiro, 2019. No prelo.

PESSOA, Thiago Campos. O império dos Souza Breves nos Oitocentos: política e escravidão nas trajetórias dos comendadores José e Joaquim de Souza Breves. 2010. Dissertação (Mestrado em História) - Universidade Federal Fluminense, Niterói. 2010.

O comércio negreiro na clandestinidade: as fazendas de recepção de africanos da família Souza Breves e seus cativos. Afro-Ásia (Salvador), n. 47, p. 43-78, 2013.

A indiscrição como ofício: o complexo cafeeiro revisitado (c.1831-c.1888). 2015. Tese (Doutorado em História) - Universidade Federal Fluminense, Niterói. 2015.

O império da escravidão: o complexo Breves no vale do café (Rio de Janeiro, c.1850-c. 1888). Rio de Janeiro: Arquivo Nacional, 2018 a.

A "delação alcoforado" e o comércio ilegal de africanos: notas de pesquisa. In: OSÓRIO, Helen; XAVIER, Regina. Do tráfico ao pós-abolição: trabalho compulsório e livre e a luta por direitos sociais no Brasil. São Leopoldo: Oikos, 2018b. p. 165-206.

Sob o signo da ilegalidade: 0 tráfico de africanos na montagem do complexo cafeeiro (Rio de Janeiro, 1831-1850). Tempo [online], v.24, n. 3, p.422-449, 2018c.

RODRIGUES, José Honório. Brasil e África: outro horizonte. Rio de Janeiro: Civilização Brasileira, 1964. 
RODRIGUES, Jaime. O infame comércio. Propostas e experiências no final do tráfico de africanos para o Brasil (1800-1850). São Paulo: Editora da Unicamp/Cecult, 2000.

. De costa a costa. Escravos, marinheiros e intermediários do tráfico negreiro de Angola ao Rio de Janeiro (1780-1860). São Paulo: Companhia das Letras, 2005.

SALLES, Ricardo. E o vale era o escravo: Vassouras, século XIX. Senhores e escravos no coração do império. Rio de Janeiro: Civilização Brasileira, 2008.

SOARES, Marcio. Compra e venda de escravos nas últimas décadas da escravidão em Campos dos Goytacazes (1861-1887).2015(mimeo.).

TAVARES, Luis Henrique Dias. Comércio proibido de escravos. São Paulo: Ática, 1988.

THE TRANS-ATLANTIC Slave Trade Database. Disponível em: http://www.slavevoyages.org/. Acesso em : 16 de março de 2019.

TOMICH, Dale. Pelo prisma da escravidão: trabalho, capital e economia mundial. São Paulo: Edusp, 2011.

VERGER, Pierre. Fluxo e refluxo do tráfico de escravos entre o golfo do Benin e a baía de Todos os Santos: dos Séculos XVII ao XIX. Salvador: Corrupio, 2002.

VON TSCHUDI, J.J. Viagem às províncias do Rio de Janeiro e S. Paulo. São Paulo: Livraria Martins Editor S/A, 1958.

WISSENBACH, Maria Cristina C. As feitorias de urzela e o tráfico de escravos: Georg Tams, José Ribeiro dos Santos e os negócios da África centro-ocidental na década de 1840. In: REIS, João José (org.) Atlântico de dor: faces do tráfico de escravos. Belo Horizonte: Fino Traço, 2016. p. 473-512

. Dinâmicas históricas de um porto centro-africano: Ambriz e o baixo Congo nos finais do tráfico atlântico de escravos (1840-1870). Revista de História (São Paulo), n.172, p.163-195, jan.-jun. 2015. 